\title{
The Effect of Various Resuscitative Regimens on Hemorrhagic Shock in Puppies
}

\author{
By William E. Strodel, Mark Callahan, William H. Weintraub, and Arnold G. Coran
}

- Since shock secondary to hemorrhage is not infrequently encountered in the pediatric patient, a puppy model was devised to help measure and monitor cardiovascular and metabolic changes that occur before and after resuscitation from hypovolemic shock (mean arterial pressure of $50 \mathrm{~mm} \mathrm{Hg}$ for $1 \mathrm{hr}$ ). Three resuscitation protocols were compared: whole blood (replacement:shed) $1: 1,5 \%$ albumin in Ringer's lactate 1:1; and Ringer's lactate 3: 1. All dogs survived the experiment and responded similarly during the shock period. Thermal dilution cardiac output rose in all groups after resuscitation; however, in the Ringer's lactate and 5\% albumin groups, cardiac output was statistically greater than that observed in the blood group. In all groups, $\mathrm{pH}$ and blood pressure approached but did not return completely to baseline levels after resuscitation. In addition, early resuscitation demonstrated a further decrease in pH ("hidden acidosis") before it began to return toward normal as resuscitation progressed. This study suggests that the infusion of large volumes of Ringer's lactate or $5 \%$ albumin in Ringer's lactate are equally efficacious in the treatment of hemorrhage. However, $5 \%$ albumin seems to be preferable because it allows infusion of a smaller quantity of electrolyte solution with equivalent physiologic benefits.

INDEX WORDS: Hemorrhagic shock; hypovolemic shock.

$\mathbf{H}$ YPOVOLEMIA secondary to blood loss can lead to low flow states and shock with resultant increased morbidity and mortality. This phenomenon occurs especially in infants, and the study that follows attempts to evaluate in puppies differences among three popular techniques for resuscitation of hemorrhagic shock: replacement with shed blood, replacement milliliter for milliliter with $5^{\circ}$, albumin in Ringer's lactate, and replacement $3 \mathrm{ml}$ for $1 \mathrm{ml}$ with Ringer's lactate.

\section{MATERIALS AND METHODS}

Eighteen mongrel puppies, each weighing $2-5 \mathrm{~kg}$. were divided into three groups. After a $12-\mathrm{hr}$ fast, each puppy was anesthetized with pentobarbital $(30 \mathrm{mg} / \mathrm{kg})$, intubated, and allowed to respire spontaneously throughout the study. Bilateral femoral cutdowns were performed for arterial and venous access. A thermodilution cardiac output catheter (American Catheter 5F) was passed into the pulmonary artery via one femoral vein using pressure tracings for positioning (the exact location was confirmed at autopsy after each experiment). Arterial pressure was monitored with a Statham 23-db strain gauge attached to a Water's PRD-15 physiologic recorder and cardiac output computer. The equipment was recalibrated before and after each experiment.

Each puppy was completely heparinized $(150 \mathrm{U} / \mathrm{kg}$ beef lung heparin) and allowed to stabilize for $30 \mathrm{~min}$. After two baseline readings $15 \mathrm{~min}$ apart were obtained. shock was induced by blood

From the Section of Pediatric Surgery, Mott Children's Hospital and University of Michigan Medical School. Ann Arbor. Mich.

Presented at the Eighth Annual Meeting of the American Pediatric Surgical Association. Acapulio. Mexico, April 20-23, 1977.

Address for reprint requests: William H. Weintraub, M.D., Section of Pediatric Surgery. Mott Children's Hospital, Ann Arbor, Mich. 48109.

ic: 1977 by Grune \& Stratton, Inc. ISSN 0023 3468. 
Table 1.

\begin{tabular}{cccc}
\hline & $N$ & $\begin{array}{c}\text { Weight } \\
(\mathbf{k g})\end{array}$ & $\begin{array}{c}\text { Blood Shed } \\
\text { (ml) }\end{array}$ \\
\hline Group 1 & 6 & $2.9 \pm 0.5$ & $100 \pm 29$ \\
Group 2 & 5 & $3.6 \pm 0.9$ & $128 \pm 37$ \\
Group 3 & 7 & $3.5 \pm 0.6$ & $139 \pm 29$ \\
\hline
\end{tabular}

withdrawal until the mean arterial pressure was approximately $50 \mathrm{~mm} \mathrm{Hg}$. Blood withdrawn for biochemical analyses was carefully accounted for as part of the total blood withdrawn to prevent a further increase in hypovolemia. After the hypotensive state was maintained for $1 \mathrm{hr}$, resuscitation was instituted. Group 1 (6) dogs received shed blood $1 \mathrm{ml}$ for $1 \mathrm{ml}$; group 2 (5) dogs were given a colloidal solution of $5_{0}^{\circ}$ albumin in Ringer's lactate $1 \mathrm{ml}$ for $1 \mathrm{ml}$; and group 3 (7) dogs received $3 \mathrm{ml}$ of Ringer's lactate per milliliter of blood shed. Each solution was infused over $15 \mathrm{~min}$.

At 15-min intervals throughout each experiment, arterial blood pressure, thermodilution cardiac output, hemoglobin, bicarbonate, pll, $\mathrm{PO}_{2}, \mathrm{PCO}_{2}$, and $\mathrm{O}_{2}$ saturation were measured. In addition, at each measurement point, blood was drawn. deproteinized with perchloric acid, and frozen for later lactate analysis.

For each measurement, the mean and standard deviation was computed. Results were compared using Student's test and were considered significant if $p<0.01$

\section{RESULTS}

\section{General}

Table 1 compares the weights and the amount of blood shed to attain shock in all three groups. There were no significant differences noted among the groups. During the baseline period, no statistical differences were seen among the three groups.

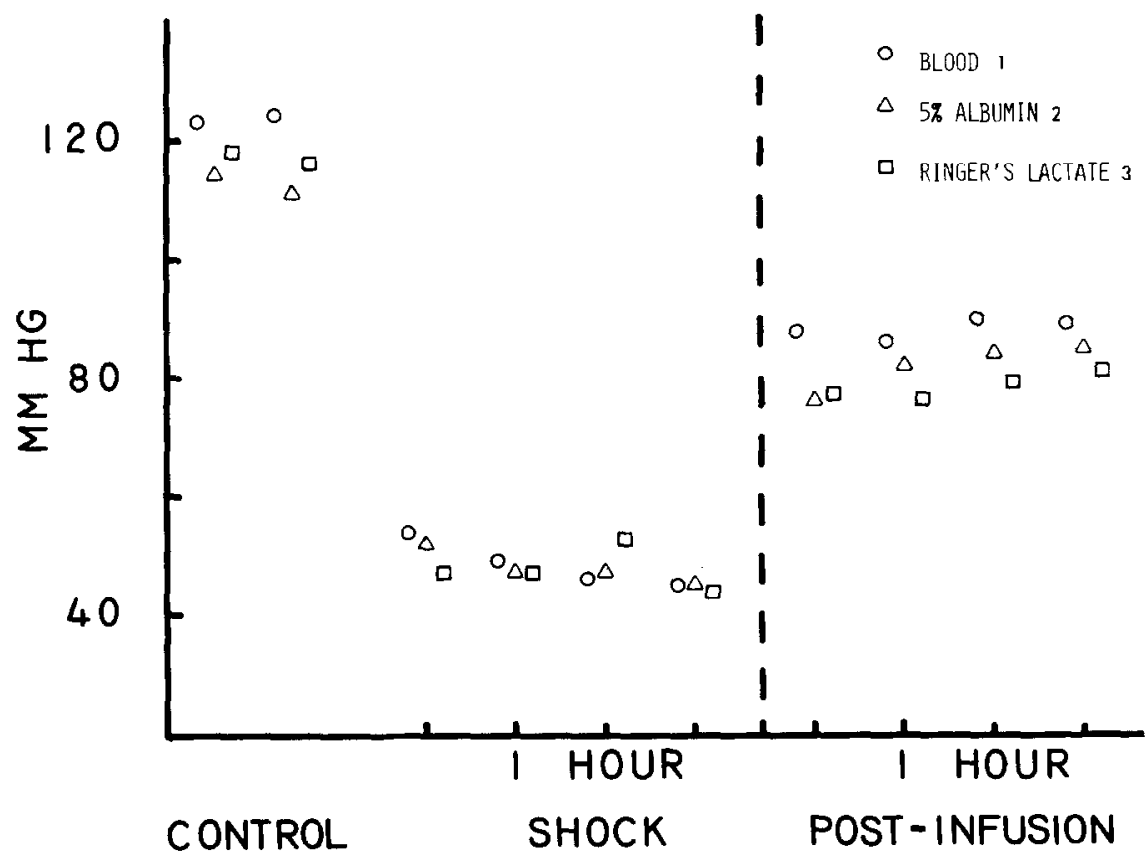

Fig. 1. Mean arterial pressure. 


\section{Mean A rterial Pressure}

Figure 1 demonstrates that throughout the shock period, the pressure remained at approximately one-half the baseline value. After resuscitation, the mean pressure rose significantly in all groups but did not attain the preshock levels. Again, no differences occurred among the groups.

\section{Cardiac Output}

During shock, cardiac outputs in all groups significantly decreased to nearly $50 \%$ of the control values (Fig. 2). Following resuscitation, output in group 1 returned to the baseline while outputs in groups 2 and 3 were greater than their initial values. During the early phase after resuscitation, the cardiac outputs in groups 2 and 3 were significantly greater than that observed in group 1 but no different when compared to each other. Subsequently, the cardiac outputs gradually decreased in groups 2 and 3 until there was no difference among the three groups at $1 \mathrm{hr}$ after resuscitation, at which point the outputs in all groups were at baseline values.

\section{Heart Rate}

As seen in Fig. 3, with the induction of shock, bradycardia developed in all groups and after resuscitation the heart rate gradually increased toward baseline levels.

\section{Hemoglobin}

Hemoglobin remained stable in the puppies in group 1 throughout shock and following resuscitation, while, as expected, it fell in groups 2 and 3 after the infusion of asanguineous fluid (Table 2).

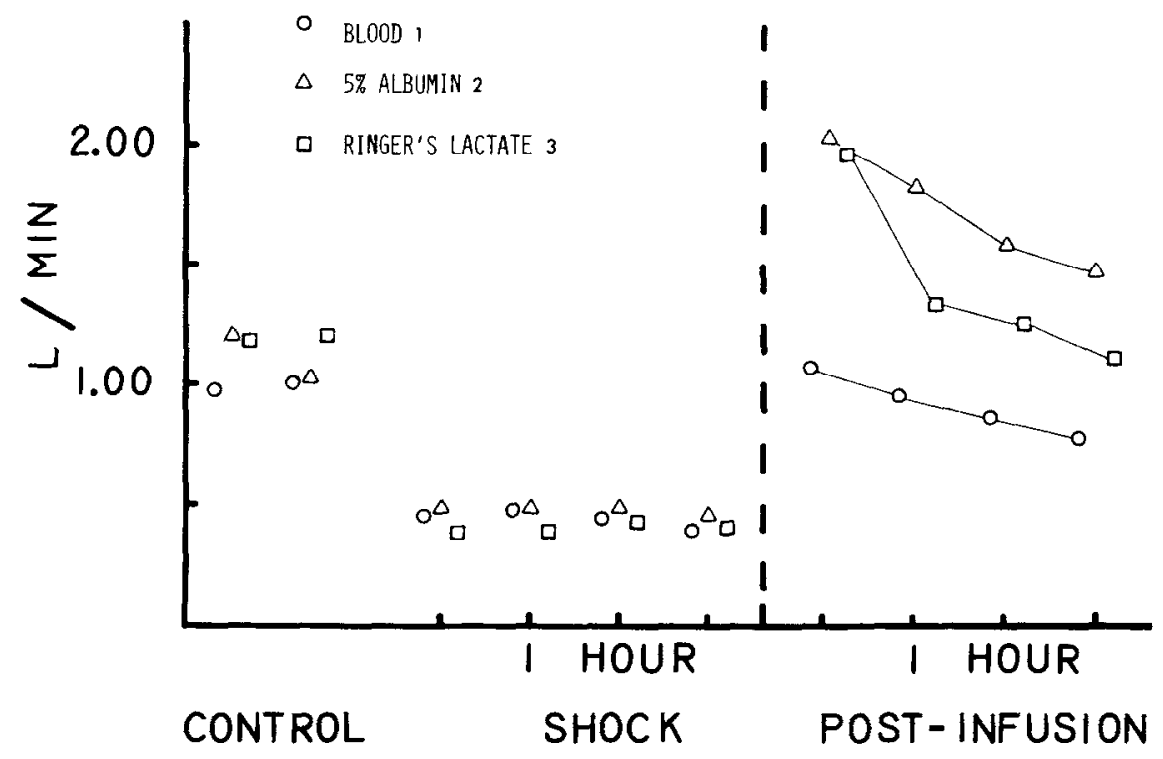

Fig. 2. Cardiac output. 


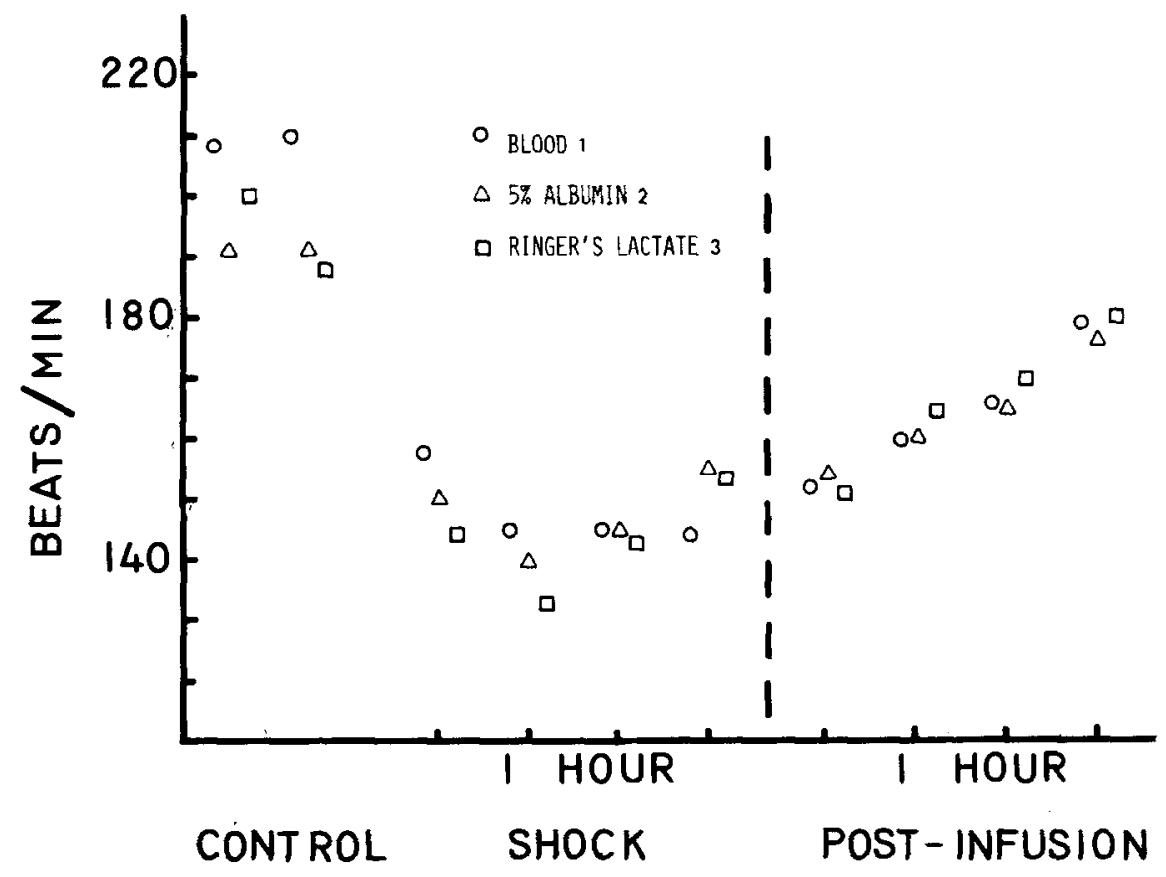

Fig. 3. Heart rate.

\section{Bicarbonate and $\mathrm{pH}$}

Both bicarbonate and $\mathrm{pH}$ fell as the shock period progressed (Tables 3 and 4). During the time immediately following resuscitation $\mathrm{pH}$ further decreased in all groups before gradually beginning a slow rise. Preshock values were not reached in any of the groups. Bicarbonate varied greatly within each group; and while no statistical difference was noted among the groups, the trend in each case was upward.

\section{Lactate}

Lactate rose significantly during shock in all groups with no difference among groups. After resuscitation, the lactate continued to rise for $15 \mathrm{~min}$ and then

Table 2. Hemoglobin Results $(\mathrm{g} / 100 \mathrm{ml})$

\begin{tabular}{lccc}
\hline & Group 1 & Group 2 & Group 3 \\
\hline Boseline & $10.0 \pm 1.2$ & $11.9 \pm 2.0$ & $11.1 \pm 1.3$ \\
& $10.3 \pm 0.9$ & $11.6 \pm 2.4$ & $10.7 \pm 1.4$ \\
Shock & $7.7 \pm 2.2$ & $10.1 \pm 1.7$ & $9.1 \pm 1.6$ \\
& $7.6 \pm 1.4$ & $9.8 \pm 2.9$ & $8.6 \pm 1.2$ \\
& $8.3 \pm 1.0$ & $8.5 \pm 1.6$ & $7.4 \pm 1.2$ \\
Resuscitation & $7.9 \pm 1.6$ & $8.6 \pm 1.1$ & $8.1 \pm 1.2$ \\
& $8.6 \pm 1.6$ & $6.1 \pm 2.1$ & $4.7 \pm 0.9$ \\
& $8.7 \pm 1.6$ & $4.2 \pm 2.2$ & $5.3 \pm 0.9$ \\
& $8.2 \pm 2.0$ & $6.0 \pm 1.6$ & $5.9 \pm 0.9$ \\
& $8.5 \pm 1.6$ & $6.0 \pm 1.9$ & $4.5 \pm 1.0$ \\
\hline
\end{tabular}


Table 3. pH Results

\begin{tabular}{llll}
\hline & Group 1 & Group 2 & Group 3 \\
\hline Baseline & $7.32 \pm 0.02$ & $7.33 \pm 0.04$ & $7.35 \pm 0.05$ \\
& $7.36 \pm 0.03$ & $7.28 \pm 0.07$ & $7.32 \pm 0.05$ \\
Shock & $7.22 \pm 0.09$ & $7.20 \pm 0.04$ & $7.25 \pm 0.06$ \\
& $7.12 \pm 0.25$ & $7.15 \pm 0.04$ & $7.18 \pm 0.09$ \\
& $7.10 \pm 0.25$ & $7.12 \pm 0.03$ & $7.14 \pm 0.09$ \\
& $7.15 \pm 0.14$ & $7.08 \pm 0.09$ & $7.18 \pm 0.06$ \\
Resuscitation & $7.06 \pm 0.22$ & $7.08 \pm 0.06$ & $7.09 \pm 0.09$ \\
& $7.09 \pm 0.20$ & $7.06 \pm 0.12$ & $7.14 \pm 0.10$ \\
& $7.13 \pm 0.21$ & $7.14 \pm 0.12$ & $7.21 \pm 0.10$ \\
& $7.22 \pm 0.24$ & $7.18 \pm 0.09$ & $7.24 \pm 0.09$ \\
\hline
\end{tabular}

declined but still remained significantly elevated over control values in all groups. Again, no differences were observed among groups (Fig. 4).

\section{$\mathrm{PO}_{2}, \mathrm{PCO}_{2}$, and $\mathrm{O}_{2}$ Saturation}

In all three groups, each of these parameters remained stable throughout the control, shock, and postresuscitation periods.

\section{DISCUSSION}

\section{Survival}

All dogs in the study survived the period of hemorrhagic shock despite the method of resuscitation employed. There are several possible reasons for this. First, Nagy et al. ${ }^{\prime}$ reported an increased tolerance and survival in 2-3-mo-old beagles to acute large unreplaced blood loss. No final conclusion was made regarding the mechanism of this tolerance. Lister et al. ${ }^{2}$ studied 6 -15-wk-old puppies and found that their homeostatic plasma volume expansion was greater than that in older dogs but was gradually reduced over the $48 \mathrm{hr}$ following hemorrhage. Second, the puppies in this study did not undergo antecedent splenectomy. Chien ${ }^{3}$ demonstrated greater intolerance to hemorrhage in dogs that had had splenectomy when compared to those that had not. At the same rate of blood loss, splenectomized dogs had greater decreases in mean arterial pressure and cardiac output. Presumably, this is due to an "autotransfusion"

Table 4. Bicarbonate Results

\begin{tabular}{llll}
\hline & Group 1 & Group 2 & Group 3 \\
\hline Boseline & $19.7 \pm 2.1$ & $16.7 \pm 2.5$ & $19.8 \pm 3.6$ \\
& $19.8 \pm 2.2$ & $14.8 \pm 1.9$ & $18.7 \pm 3.3$ \\
Shock & $12.3 \pm 4.0$ & $13.8 \pm 1.5$ & $12.9 \pm 2.3$ \\
& $11.3 \pm 4.4$ & $13.2 \pm 3.3$ & $11.3 \pm 3.3$ \\
& $13.7 \pm 4.6$ & $10.9 \pm 3.4$ & $10.7 \pm 2.4$ \\
Resuscitation & $11.0 \pm 4.1$ & $10.1 \pm 3.1$ & $11.3 \pm 1.3$ \\
& $11.0 \pm 5.3$ & $10.8 \pm 1.9$ & $10.2 \pm 3.0$ \\
& $12.5 \pm 5.8$ & $11.7 \pm 1.5$ & $11.4 \pm 3.9$ \\
& $12.5 \pm 5.7$ & $13.5 \pm 1.9$ & $12.6 \pm 3.5$ \\
& $13.8 \pm 5.6$ & $13.7 \pm 2.4$ & $13.4 \pm 3.4$ \\
\hline
\end{tabular}




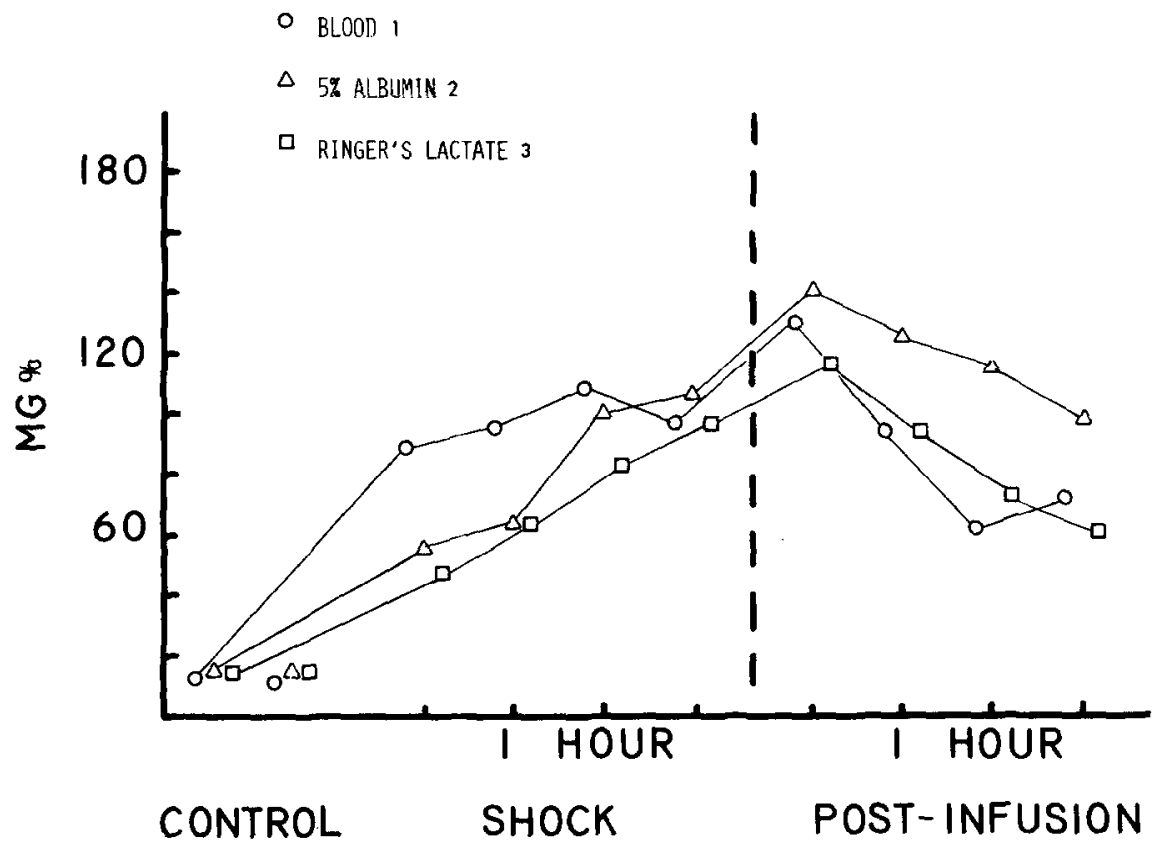

Fig. 4. Serum lactate.

effect produced by the contracting spleen. Finally, even though the quantity of blood shed was approximately $35 \%$ of the estimated blood volume, the mean arterial pressure was maintained at $50 \mathrm{~mm} \mathrm{Hg}$ during shock. This pressure is $10-15 \mathrm{~mm} \mathrm{Hg}$ higher than that achieved in most hemorrhagic shock experiments associated with high mortalities. ${ }^{1,3,4}$ However, despite zero mortality, the dogs in this study met the criteria for shock by demonstrating significant decreases in cardiac output and increases in lactate.

\section{Blood Gases}

Pulmonary insufficiency has been raised as an issue in hemorrhagic as well as septic shock; however, in most cases, concomitant trauma has been associated with the shock. ${ }^{5-8}$ Harrison et al., in a recent study, reported ultrastructural changes in the lungs of puppies subjected to hypoxia and hemorrhagic shock. ${ }^{9}$ These dogs were not resuscitated so that the reversibility of these lesions was not tested. $\mathrm{PO}_{2}, \mathrm{PCO}_{2}$, and $\mathrm{O}_{2}$ saturation in all groups remained essentially unchanged throughout the present study. Moss et al. ${ }^{10}$ studied compliance, minute volume, and total lung volumes as well as blood gases and found no significant differences among his resuscitation groups. Silberschmid ${ }^{11}$ and Soma et al. ${ }^{12}$ also reported no major pulmonary structural changes or impairment of gas exchange during hemorrhagic shock in dogs. Sayeed and Baue found that the respiratory activities of lung mitochondria were not altered by shock. ${ }^{13}$ If not a direct pulmonary insult, perhaps hemorrhagic shock renders the lung more vulnerable to other subsequent or concomitant insults such as sepsis or major organ injury. 


\section{Cardiac Output}

Each group studied quickly responded to resuscitation with increased cardiac output; however, they varied according to the degree to which they responded. When cardiac output is plotted against venous pressure, it can be seen that cardiac output increased with increased venous pressure up to a point, after which cardiac output plateaus and eventually decreases as the myocardium begins to decompensate. ${ }^{14}$

The Ringer's lactate group represents a situation in which a large fluid volume was used, thus resulting in a greater cardiac output than that measured in the group resuscitated with shed blood milliliter for milliliter. Since there was no significant difference between the cardiac outputs in the albumin and Ringer's groups in the initial phases after resuscitation, it is apparent that the volume of $5 \%$ albumin infused was sufficient and certainly as effective as the larger volume of Ringer's lactate. This may be accounted for by increased intravascular oncotic pressure in the albumin group and the improved hemodynamic properties of hemodilution. In both groups 2 and 3, the cardiac outputs gradually decreased after the initial peak following resuscitation. The mean cardiac output in the Ringer's group declined faster than that observed in the albumin group, probably because the rate of diffusion of crystalloid (Ringer's lactate) into the interstitium is greater than albumin.

According to Starling's hypothesis, infusion with albumin increases the intravascular colloid oncotic pressure and thus slows the diffusion of water from the intravascular space, perhaps even causes an influx of crystalloid from the interstitium into the capillaries. However, this concept applies only in physiologic states and not pathologic ones in which the capillaries are more permeable. It appears that during hemorrhagic shock, albumin does leak into the interstitium. Getzen et al. demonstrated a significant fall $(20 \%)$ in the serum protein concentration $15 \mathrm{~min}$ after hemorrhage. ${ }^{15}$ Subsequently, the protein continued to fall but at a much slower rate. Others report a "leak" into the interstitial space of $5 \%-15 \%$ per hr after the infusion of concentrated albumin. ${ }^{16}$ Experimental evidence in the neonate suggests that the rate of capillary escape is 3-4 times that seen in adults and that the lung in particular may be susceptible to interstitial sequestration. ${ }^{17,18}$ However, as a result of the present study, it appears that this "leak," if it occurs, is not hemodynamically significant since mean cardiac output in the albumin group remained greater than its control values and greater than that measured in the blood group during the early phase after resuscitation. Perhaps the permeability of the capillary endothelium is increased in hypoxic states, e.g., decreased cardiac output and poor tissue perfusion. The immediate response seen in the resuscitation of hemorrhagic shock is increased cardiac output and increased mean arterial pressure, thus resulting in a shift back to oxidative metabolism as perfusion improves. As a result, some albumin may diffuse into the interstitium, but this diffusion may be limited by the degree and speed of return of perfusion to normal. ${ }^{19}$

\section{Blood Pressure and Heart Rate}

Although mean arterial pressure increased after resuscitation in all groups, it did not return to preshock levels. This finding has been previously observed 
by several investigators, including Baue et al. ${ }^{20}$ and is attributed to a decrease in total peripheral resistance secondary to the vasodilatory effects of increased blood lactate values. In this study the lactate never returned to the control value.

All dogs demonstrated a bradycardic response to shock. This phenomenon is well described in the neonatal $\operatorname{dog} ;{ }^{1,2,21,22}$ while the puppies used in this study were not neonates, it appears that their hemodynamic response to hemorrhage was comparable to that observed in neonatal dogs.

\section{Metabolic Changes}

As expected, serum lactate increased during shock while $\mathrm{pH}$ fell..$^{23}$ Early after resuscitation, the mean arterial $\mathrm{pH}$ continued to decrease despite increased mean arterial pressure and improved cardiac output. This has been described by Litwin et al. as "hidden acidosis." ${ }^{4}$

Despite the lack of oxygen-carrying capacity in the solutions used in groups 2 and 3 , they were able to partially correct the metabolic acidosis and prevent further increases in lactate levels in a manner similar to that seen in the puppies given whole blood. This confirms the concept that restoration of vascular volume by any fluid will improve oxidation and correct the metabolic changes that occur with shock if it is administered before the shock becomes "irreversible." This hemodilution state can usually be tolerated acutely because of the better flow characteristics (reduced intravascular sludging and reduced sequestration of red blood cells) as well as the increased cardiac output of diluted blood. ${ }^{25-28}$ On the other hand, in cases in which more than moderate blood loss occurs, progressive hemodilution could become a disadvantage as the oxygen-carrying capacity decreases. The excessive hemodilution that follows massive Ringer's infusion also leaves the organism with little reserve to sustain further insult such as infection or sepsis. In agreement with the results of this study, others have reported no apparent change in the serum lactate after infusion of Ringer's lactate. ${ }^{29,30}$

Several investigators have studied resuscitation of hemorrhagic shock in the adult model. The pediatric model has been less extensively evaluated. It is clear that asanguineous fluids are the cornerstone of the acute management of hemorrhagic shock, but it remains to be seen which of the various fluids available are superior. Moss et al. compared the use of normal saline and blood in shock resuscitation. ${ }^{10}$ Each were found to be equally efficacious in returning cardiovascular parameters to preshock levels. The only difference was that the saline group was more acidotic at the conclusion of resuscitation. Coran et al ${ }^{30}$ studied the effect of saline against Ringer's lactate in dogs. Here too, the cardiovascular parameters were not significantly different between groups during and following resuscitation. The only difference was a lower $\mathrm{pH}$ in the saline-infused group. This finding was attributed to the lack of buffers in normal saline solution and their presence in Ringer's lactate. Zollman et al. ${ }^{31} \mathrm{com}$ pared shed blood to shed blood plus Ringer's lactate and found no difference in survival, however, their groups were small in number. Laks et al. ${ }^{32}$ evaluated crystalloid versus colloid hemodilution and found that Plasmanate reduced lung water and decreased the arteriovenous oxygen gradient. Although these 
studies were not carried out in the shock state, they do indicate more specifically the favorable hemodynamic response to hemodilution by both crystalloid and colloid solutions.

Large volumes of Ringer's lactate are usually well tolerated in the young and otherwise healthy organism; however, pulmonary edema is not an uncommon complication since crystalloid solution is not completely and indefinitely retained in the intravascular space. Rowe ${ }^{33}$ reported normal saline infusion of 13 times the total blood volume before pulmonary edema resulted in death. Large infusions of Ringer's lactate or normal saline can also lead to sodium retention and increased serum osmolarity since the infant kidney excretes dilute urine and has a decreased capacity to excrete sodium.

This study suggests that crystalloid and colloid solutions result in a better hemodynamic response (as measured by cardiac output) than does whole blood because of the decreased capillary sludging and increased flow characteristics of hemodiluted blood. In the case of Ringer's infusion, increased volume played a significant role, while in the case of the infusion of $5 \%$ albumin, increased intravascular oncotic pressure was important. It would appear that $5 \%$ albumin might be preferable to Ringer's lactate because it allows infusion of a smaller quantity of electrolyte solution with equivalent physiologic benefits.

\section{REFERENCES}

1. Nagy S, Deavers $S$, Huggins R: Tolerance to blood loss in the growing beagle. Proc Soc Exp Biol Med 137:1163, 1971

2. Lister $\mathbf{J}$, Altman $\mathbf{R}$, Win $\mathbf{M}$, et al: Homeostatic responses to alteration of blood volume in puppies. I. Hemorrhage. J Pediatr Surg 2: 241,1967

3. Chien S: Quantitative evaluation of circulatory adjustment of splenectomized dogs to hemorrhage. Am J Physiol 193:605, 1958

4. Swan H, Blavier J, Marhioro J, et al: Experimental hemorrhage: Prediction of mortality following acute measured hemorrhage in the dog. Arch Surg 79:176, 1959

5. Lowery B, Cloutier C, Carey L: Blood gas determinations in the severely wounded in hemorrhagic shock. Arch Surg 99:330, 1969

6. Connell RS, Swank RL: Pulmonary fine structure after hemorrhagic shock and transfusions of aging blood. Microcirculatory approach to current therapeutic problems. Symposium VI European Conference on Microcirculation, Aalborg, Denmark, 1970

7. Kallos T, Wyehe MQ, Marshall BE: Effect of hemorrhagic shock on pulmonary diffusion and capillary blood volume. J Trauma $13: 218,1973$

8. Swank RL, Edward MS: Microvascular occlusion by platelet emboli after transfusion and shock. Microvasc Res 1:15, 1968

9. Harrison M, Connell R, Campbell J, et al:
Microcirculatory changes in the lung of the hypoxic and hypovolemic puppy: An electron microscope study. Ann Surg 185:311, 1977

10. Moss G, Proctor H, Homer L, et al: A comparison of asanguineous fluids and whole blood in the treatment of hemorrhagic shock. Surg Gynecol Obstet 129:1247, 1969

11. Silberschmid $\mathbf{M}$ : Hemorrhagic shock in dogs without major pulmonary changes. Eur Surg Res 7:10, 1975

12. Soma L, Neufeld G, Dodd, et al: Pulmonary function in hemorrhagic shock: The effect of pancreatic ligation and blood filtration. Ann Surg 179:395, 1974

13. Sayeed $M$, Baue A: Mitochondrial metabolism of succinate, hydroxybutyrate, and ketoglutarate in hemorrhagic shock. Am J Physiol 220:1275, 1971

14. Guyton A: Textbook of Medical Physiology. Philadelphia, Saunders, 1966

15. Getzen L, Pollak E, Wolfman E: Serum protein concentration during hemorrhagic shock. Surg Gynecol Obstet 144:42, 1977

16. Marty A: Hyperoncotic albumin therapy. Surg Gynecol Obstet 139:105, 1974

17. Parving $\mathbf{H}$, Klebe $J$, Ingoman $C$ : Simultaneous determination of plasma volume and transcapillary escape rate with $I^{131}$ labelled aibumin and T-1824 in the newborn. Acta Paediatr Scand 62:248, 1973

18. Boonyaprakod U, Taylor P, Watson D, 
et al: Hypoxia and protein clearance from pulmonary vascular beds of adult dogs and pups. Am J Physiol 216:1013, 1969

19. Zollinger R: Plasma volume and protein restoration after hemorrhage: Role of the left thoracic duct versus transcapillary refilling. J Surg Res 12:151, 1972

20. Baue $A$, Tragus $E$, Wolfson $S$, et al: Hemodynamic and metabolic effects of Ringer's lactate solution in hemorrhagic shock. Ann Surg 166:29, 1967

21. Hollman G: Experimental studies of peculiar pathological physiology of shock in early infancy. Ann Chir Inf 13:123, 1972

22. Rowe M, Arcilla R: Hemodynamic adaptation of the newborn to hemorrhage. J Pediatr Surg 3:278, 1968

23. Daniel A, Pierce C, MacLean L, et al: Lactate metabolism in the dog during shock from hemorrhage, cardiac tamponade or endotoxin. Surg Gynecol Obstet 143:581, 1976

24. Litwin $\mathbf{M}$, Bergentz S, Carsten $A$, et al: Hidden acidosis following intravaseular red blood cell aggregation in dogs: Effects of high and low viscosity dextran. Ann Surg 161:532, 1965

25. Cervera A, Moss G: Dilutional reexpansion with crystalloid after massive hemorrhage: Saline versus balanced electrolyte solution for maintenance of normal blood volume and arterial pH. J Trauma 15:498, 1975
26. Reich M, Eiseman B: Tissue oxygenation following resuscitation with crystalloid solution following experimental acute blood loss. Surgery 69:928, 1971

27. Replogle R, Merrill E: Hemodilution: Rheologic, hemodynamic and metabolic consequences in shock. Surg Forum 18:157, 1967

28. Hunt $\mathbf{I}$, Bengt $\mathbf{H}$, Goldstick $\mathrm{T}$ : Tissue $\mathrm{O}_{2}$ tensions during controlled hemorrhage. Surg Forum 18:3, 1967

29. Trinkle J, Rush B, Eiseman B: Metabolism of lactate following major blood loss. Surgery 63:782, 1968

30. Coran A, Ballantine T, Horwitz D, et al: The effect of crystalloid resuscitation in hemorrhagic shock on acid-base balance: A comparison between normal saline and Ringer's lactate solutions. Surgery $69: 874,1971$

31. Zollman W, Culpepper R, Turner $M$, et al: Hemorrhagic shock in dogs. Comparison of treatment with shed blood alone versus shed blood plus Ringer's lactate: Intravascular pressures, cardiac output, oxygen consumption, arteriovenous oxygen differences, extracellular fluid $\mathrm{PO}_{2}$, electrolyte changes and survival rates. Am J Surg 131:298, 1976

32. Laks H, O'Connor $\mathbf{N}$, Anderson $\mathbf{W}$, et al: Crystalloid versus colloid hemodilution in man. Surg Gynecol Obstet 142:506, 1976

33. Rowe $M$ : The neonatal response to massive fluid infusion. J Pediatr Surg 6:365, 1971

\section{Discussion}

$H$. Blanchard (Montreal): I would like to ask the authors if they have studied the loss of albumin into the interstitium of the lungs or throughout the body. Have they thought about studying the effect of albumin on tubular reabsorption of water and sodium?

R. Touloukian (New Haven): Perhaps you could tell us what percentage of the total circulating blood volume was shed in the hemorrhage experiment. I think it's an important question when the dog is used as the animal model, since the spleen is a muscular contractile organ and does autotransfuse the subject. Could you speculate about whether or not the results of this study apply to the management of hypovolemic shock in young children or infants?

J. O'Neill (Nashville): I wonder if you have any figures relative to plasma volume in these subjects. Certainly the sine qua non of resuscitation is improvement and maintenance of good cardiac output, but if one is comparing resuscitation regimens on an acute basis, that is, on a l-hr basis like this, it might be well to know the plasma volume. The reason I ask is that the selection of $3 \mathrm{ml}$ replacement per milliliter of shed blood is perhaps a little shy on the basis of estimates made originally by Dr. Moyer indicating a ratio of at least $3.2: 1$ and as high as $4: 1$ in some of his experimental animals.

W. Strodel (Closing): Dr. Blanchard, although we did not study the kinetics of albumin "leakage" into the pulmonary interstitium, this is an interesting point and has been evaluated by others. It remains controversial whether the amount lost is clinically significant and whether the net effect is detrimental to the organism.

Dr. Touloukian, the amount of blood shed in each group of dogs was approximately $35 \%$ of the total estimated blood volume. There was no significant difference among the three groups. 
Certainly the effects of autotransfusion from a contracted splenic bed are important to survival and have been previously reported. None of the dogs in the present study underwent antecedent splenectomy and all survived.

Dr. O'Neill, plasma volume measurements were not determined in this study. We are currently investigating this parameter. The choice of 3:1 Ringer's lactate replacement derives from the work done previously by Shires in the treatment of hemorrhagic shock. Recent studies by Moss indicate that any dilution short of 8:1 may be inadequate. We are also currently investigating this question. 